the paper with its center located at $p$. Concentrated at each end of the $\operatorname{rod} 1-2$ are equal masses $m, m$, each distant $r$ from $p$. Let $R$ equal the distance $O-p, x$ the distance $O-1$, and $y$ the distance $O-2$.

When the system revolves about $O$ as center, the point $p$ will have a linear velocity;

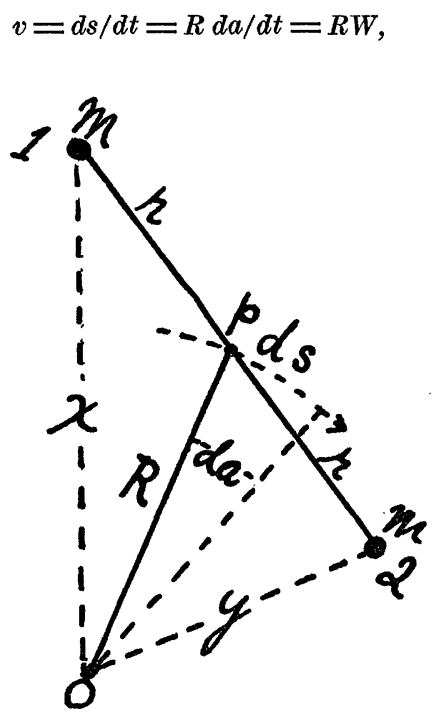

FIG. 1

where $d s$ is the element of arc described in time, $d t, d a$ is the differential angle through which $O-p$ turns and $W$ is the angular velocity of $O-p$.

1. Assume that the $\operatorname{rod} 1-2$ is free to turn on $p$ as center. Since $m$ at 1 and $m$ at 2 are equal and equally distant from $p, p$ is the center of mass. No motion, force or acceleration which exists at the point $p$ can produce rotation of $1-2$ about $p$ as center. This must be so, as it is axiomatic in dynamics that, when there is a force or acceleration at the center of mass only of a body, there remains no couple to produce rotation of the mass, and by Newton's first law, a force must act before a mass can change its state of rest or motion.

In the condition, where $1-2$ is free to turn about $p$, the kinetic energy then of the system must be,

$$
E^{\prime}=\frac{1}{2}(2 m) v^{2}=m R^{2} W^{2}
$$

2. Conceive the rod, $1-2$, to become rigidly attached at $p$. Then, as $O-p$ revolves about $O$ with angular velocity $W, 1-2$ also revolves about $p$ with like angular velocity. By making the attachment at $p$ rigid the system is forced to take on an additional kinetic energy which can be only that, which is a result of the additional motion now possessed by $m$ at 1 , and by $m$ at 2 , in virtue of their rotation about $p$ as center. This added kinetic energy is:

$$
E^{\prime \prime}=\frac{1}{2}(2 m) r^{2} W^{2}=m r^{2} W^{2} .
$$

Hence, the total kinetic energy of the system when $1-2$ is rigidly attached at $p$, is :

$$
E=E^{\prime}+E^{\prime \prime}=m W^{2}\left(R^{2}+r^{2}\right) .
$$

3. With the attachment still rigid at $p$, the kinetic energy of $m$ at 1 is, plainly, that which is due to its rotation, at distance $x$, about $O$ as center, and this is

$$
E_{0}^{\prime}=\frac{1}{2} m x^{2} W^{2} .
$$

Likewise, the kinetic energy of $m$ at 2 about $O$ as center is

$$
E_{0}{ }^{\prime \prime}=\frac{1}{2} m y^{2} W^{2} .
$$

The total kinetic energy must be the sum of these two, or

$$
E=E_{0}^{\prime}+E_{0}^{\prime \prime}=\frac{1}{2} m W^{2}\left(x^{2}+y^{2}\right) .
$$

Expressions (3) and (6) are both true expressions for the same kinetic energy and hence they may be equated, giving as result,

$$
\frac{1}{2}\left(x^{2}+y^{2}\right)=R^{2}+r^{2} \text {. }
$$

In (7) we have a geometrical relation of some interest, but in the particular case when $y=x$, that is, when line $1-2$ is perpendicular to line $O-p$, we have the result,

$$
x^{2}=R^{2}+r^{2} \text {. }
$$

Thus it is proved by dynamical considerations only that in a right-angled triangle the square on the hypothenuse is equal to the sum of the squares on the other two sides.

EDwin F. NorthruP

Palmer Physical laboratory,

Princeton, N. J.,

October 7, 1910

\section{WOMEN AND SCIENTIFIC RESEARCH}

There are now nearly as many women as men who receive a college degree; they have on the 
average more leisure; there are four times as many women as men engaged in teaching. There does not appear to be any social prejudice against women engaging in scientific work, and it is difficult to avoid the conclusion that there is an innate sexual disqualification. ... But it is possible that the lack of encouragement and sympathy is greater than appears on the surface, and that in the future women may be able to do their share for the advancement of science. ${ }^{1}$

The article affording this quotation commands attention on aecount of both the method used and the results reached. In a field where impression, conjecture and personal bias play a large, if not a determining rôle, one must welcome such a well-considered plan for employing a statistical and hence impersonal method. Figures have no feelings. Perhaps none of the results set forth are more striking than the statement that in 1910 only eighteen women are to be found in the first thousand scientifie persons. A search for the causes of this fact is in itself a sociological task meriting some expenditure of scientific effort. Would the author of the article referred to be willing to call his "conclusion" a hypothetical explanation, and to admit one or two competing hypotheses?

As matters stand at present in America a young woman can not fairly complain that she is denied opportunity to study science. If one institution refuses admission to her, another equally good opens wide its doors; if some eminent professor denies her a place in his laboratory, another, equally eminent, will welcome her. But is such opportunity all that is involved? Did the young woman have a fair chance as a little girl? It would appear, on the face of it, that girls and boys in these days and this country enjoy equal opportunities. They may read the same books and play the same games; they pass through the same grade schools and, in most towns, the same high school; finally, they receive, as a rule, the same preparation for college. But is even this all that is involved?

Whoever will watch groups of girls and boys

1 "Further Statistical Study of American Men of Science," Scrence, November 11, 1910. in any grade school must realize that out of sight, in the homes, distinctions are introduced which result ultimately in mental handicap for the girl. This discrimination manifests itself primarily in compelling her attention in matters of dress. Observe the hat constructed for the little girl's wearing and contrast it with the cap worn by a boy of her own age. Good brains go to waste under a hat like that because it must receive the attention that the boy may save to bestow on a hundred things worth while. The rest of the girl's apparel corresponds of course to her hat. What is the prevailing style, how shall her clothes be made and trimmed, and does she look pretty in them, are considerations that grow with the girl's growth. If she is destined to be a member or, let us say, an associate member of the leisure class she can not proceed far in her teens before her social environment compels acceptance of the notion that a girl must be, first of all, attractive and pleasing -if possible, a social ornament. A girl is free to elect science in the high school, but what does the freedom avail if science appears undesirable on the ground that it in no way contributes to her accomplishments. Further than this, a girl loses as a rule the informal preparation for science that a boy secures. The proprieties and dainty clothing cost her many a lesson that her brother learns; and who concern themselves to take a girl to the blacksmith shop, the power-house, and the stone-quarry, to the places where the steamshovel and the pile-driver are at work. Yet it was a little girl who once asked, "Why do the cars lean in when they go around a curve?" a little girl also who concluded her explanation of a home-made filter by saying, "And so, you rinse the water with gravel." Given the same circumstances, including the circum: stance of encouragement, and it is hardly to be doubted that the rational curiosity to know the causes of things would be found in girls as it is in boys. Opportunity is rendered ineffective and the world of natural phenomena inviting to observation and analysis is denied to girls because they are assigned to an artificial environment demanding, an emotional re- 
sponse; and then we wonder at it when young women in their junior and senior years in college elect music and literature in preference to mechanics and physiology; we wonder and we frame theories about feminine predilections.

Is there any other cause, operating perhaps with the one just described, that may account for the less than two per cent. Table $X$. in the statistical study gives the number of scientific men connected with institutions when there are three or more. Fifty-eight institutions appear in the list with a total of 762 men. Let us drop from this list the four colleges for women. They will scarcely be missed since they take only nineteen of the 762. Of this list of fifty-four institutions just which ones open their major positions freely and fairly to persons of gifts and attainments without regard to sex? By a major position is meant one that a man of the select first thousand would be willing to occupy. Women are quite welcome to become experts in washing bottles and adding logarithms and dusting specimens. Even in the case of high school science the best positions in physics and chemistry are reserved for men. A young woman, however strongly inclined to devote herself to science, may well hesitate to proceed to a science doctorate when she considers that Table $\mathrm{X}$. There is indeed room for doubt whether we should have any thousand men of science if all gifted and ambitious young men were confronted by such barriers as a young woman is obliged to face to-day. We should find these young men going into literature, law, politics, business; but scarcely into science. It appears therefore difficult to avoid the conclusion that other factors besides innate sexual disqualification must be reckoned with in attempting to account for the insignificance of women's share in the advancement of science.

ELLen Hayes

\section{EMINENCE OF WOMEN IN SCIENCE}

To the Editor of Science: In Dr. Cattell's "Statistical Study of American Men of Science" occurs the following comment on the

\footnotetext{
${ }^{ \pm}$Salence, November 11, 1910, p. 676.
}

fact that there are "only 18 women among 982 men:" "There are now nearly as many women as men who receive a college degree; they have on the average more leisure; there are four times as many women as men engaged in teaching." In view of a preceding statement (p. 675) that "the advancement of science depends mainly on those who hold chairs in our colleges and universities," I would suggest that, before drawing "the conclusion that there is an innate sexual disqualification," there should be added to the premises from which any conclusion is drawn the well-known fact that, except in some of the women's colleges where the opportunities for research are limited and the salaries notably low, women are not considered eligible for chairs in the sciences named. If they have any positions in the departments at all, it is chiefly as laboratory assistants.

Another conclusion which might be drawn is that women in larger proportions than men (p. 675) are in the class of "amateurs" or scientific persons who, not needing to earn their living, devote their lives to scientific research.

It is indeed "possible," as the author says, that "the lack of encouragement and sympathy is greater than appears on the surface." Until women are more generally given an equal chance with men in academic recognition and remuneration, it is futile to attempt to determine, in terms of statistical tables or even of scientific reputation or eminence, how much "they are able to do for the advancement of science."

$$
\begin{aligned}
& \text { Marion Talbot } \\
& \text { The University of Chicago, } \\
& \text { November 14, } 1910
\end{aligned}
$$

\section{THE CENTURY DICTIONARY SUPPLEMENT}

IN the supplement to the Century Dictionary which has recently been issued, my name appears as the responsible editorial contributor for terms in plant physiology. This is an error which, I am informed by the editor of the Century Dictionary, will be corrected in subsequent copies of the supplement. I did revise the terms in plant physiology for the 